\section{Sitting for your portrait}

John M Stronge

Over the past 50 years it has become tradition for the retiring master of the National Maternity Hospital, Dublin, to have a portrait painted to mark his seven years of office. Facing this prospect in 1990, I had little guidance apart from an article on commissioning a portrait. ${ }^{1}$

My experience of painting was minimal; I consulted friends who run an art gallery, who advised me that I should have my portrait painted by Andrew Festing. I was interested that he liked to paint not only the likeness but also objects of special significance to the sitter. After viewing some of his portraits I wrote to Andrew Festing to ask him to paint my portrait, indicating that it would be hung in the hospital board room beside the portraits of the 12 previous masters. He replied accepting the commission and indicated the approximate cost, but the portrait would have to wait 18 months because he was committed to other workI must take my place in the queue. I decided that he must be a good painter if he was committed so far in advance. The delay might also help to soften the facial wrinkles that had developed in seven stressful years.

About a year later my wife and I visited the painter in his studio. I feel that the hours spent discussing the picture were the most important part of planning the portrait, which was to be a three quarter length oil on canvas of me seated at a desk. I was anxious to get away from the hats and gowns that my predecessors had favoured and to be painted in clothes that did not indicate an academic or medical background. This seemed to please the artist and we agreed the colour of the suit, tie, and shirt-which was to be striped. Considerable discussion took place over the props that would be incorporated in the picture. I was anxious that my interest in the partographic representation of

National Maternity Hospital, Dublin 2, Republic of Ireland John M Stronge, consultant in obstetrics and gynaecology

BMF 1992;305:1539-40

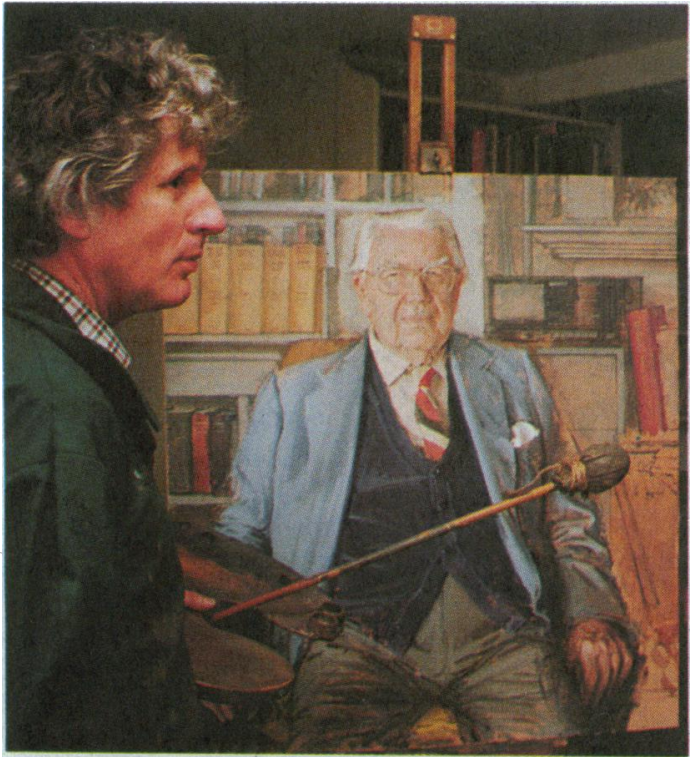

The artist with his maulstick

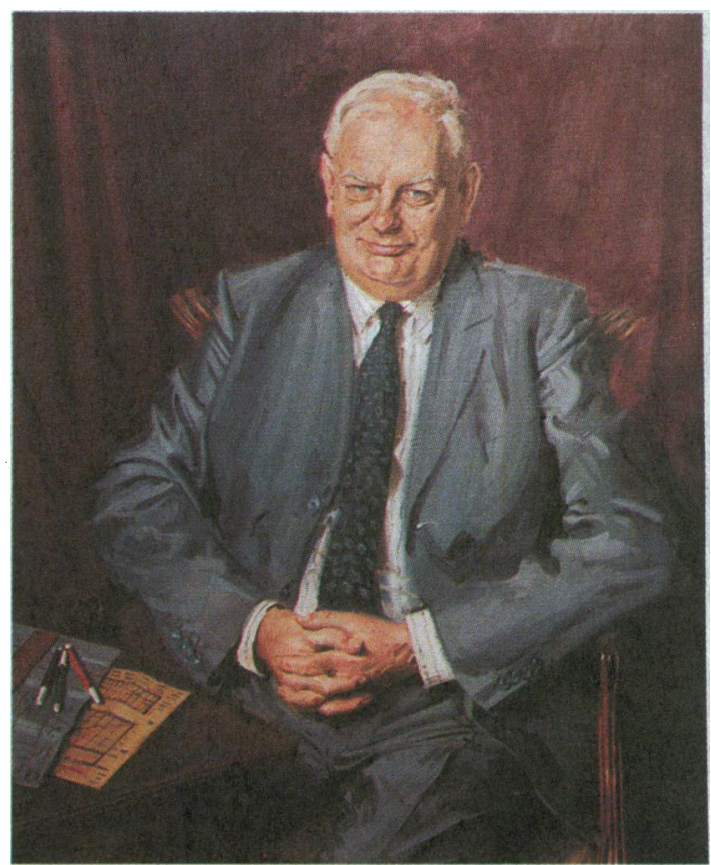

The finished portrait

labour should appear in the picture. We agreed to include a yellow and blue coloured partogram ${ }^{2}$ and a ruler and pencils. A week for the sitting was decided, four months hence. Finally we agreed a price, which included the framing, and we discussed how the finished painting would be transported to Dublin.

In March 1992 my wife and I arrived in a West Kensington hotel within walking distance of the artist's studio. The first morning was spent arranging the pose for the painting. I did not realise that my chair would be on a dais a few feet above the floor; this was so that the artist could paint me at his level when standing before the canvas. After the pose was set the artist took a series of photographs of my head with a handheld camera. This is standard procedure and allows the painter to consider proportions at leisure.

The sitting lasted for five days. At the end I was exhausted, and I recommend others to be painted over the more usual weekly or fortnightly intervals. The sittings lasted from 9 am to $5 \mathrm{pm}$, with a one hour break for lunch. I could break the pose at any time and move about the studio and view the progress of the picture, but because my time was limited I did not use this privilege very often. The radio constantly played music and the artist was happy to answer questions and to explain exactly what he was doing.

Lunch each day was a major event. Pub lunches were not advised as sitters can be difficult to extract from the pub and alcohol often alters the appearance. Instead we ate in the artist's kitchen, usually a salad with cold ham washed down with cups of coffee.

At the end of the first day the artist had sketched a 
broad outline of the picture. The next day, involving the most challenging part of the commission, painting the head and face, was the most trying day for me because I was unable to move my head without upsetting the pose. The artist often consulted the photographs and to my surprise used a tape measure to determine the relationships between various parts of my face. The technique of facial measurement derives from Holbein, the sixteenth century Dutch portraitist. Quick facial sketches are satisfactory for street corner artists using crayons on paper but not for a serious portrait.

The artist's equipment consists of a palette and many brushes of various thicknesses, but most fascinating was his maulstick. This is a pole-like device that allowed him to maintain a steady hand for fine detail.

The third day, spent painting the hands, was a more relaxed time for me as I could move my head, but I could not read until this part of the painting was completed. The next two days were spent painting the body and the clothes. These were easy days for me and it was satisfying to see progress in the painting after each session.

After five days the painting was almost complete. Adding the finishing touches to the figure and painting the props and background took about two weeks, after I had returned home. The artist agreed that he would supervise the framing of the picture, and the lettering on the label was decided. There are only three professional framers in London; framers are also responsible for varnishing the picture.

Two months after the sitting the finished portrait arrived in Dublin. It was a pleasing likeness, even if the figure was somewhat portly. The sitting was made tolerable by the courtesy of the artist, whose cheerful manner kept me amused for five days. It was a learning experience, and I gained an artist as a friend.

1 Sheeran I. How to commission a portrait. BMF 1989;299:37-9.

2 Turner MJ, Rasmussen MJ, Stronge JM. Active management of labour Fet Med Rev 1991;3:67-72.

\title{
Dickens and doctors: vignettes of Victorian medicine
}

\author{
J E Cosnett
}

Doctors are prominently represented in Charles Dickens's fiction. In 14 major works there are at least 27 members of the medical profession, some named, others anonymous. The main medical personalities provide vignettes of Victorian medicine, seen through the eyes of a very observant, critical, and socially conscious layman.

\section{Africa}

Durban, Natal, South

J E Cosnett

\section{Correspondence to:} 268 Manning Road, Glenwood, Durban 4001, Natal, South Africa. lifestyle. Sam Weller introduced Sawyer and Allen to Pickwick as "not reg'lar thoroughbred sawbones." Pickwick attributed their lack of social graces to "eccentricities of genius." Like later generations of students, they relish their esoteric status and ability to shock their lay friends with privy talk such as "Nothing like dissecting to give one an appetite." They discuss a "good accident brought into the casualty ward." They have riotous drinking parties in lodgings for which the bill is in arrears, and their landlady describes them as a "parcel of young cutters and carvers of live peoples' bodies, that disgraces the lodgings."

Another sight of medical studies is given by Richard Carstone in Bleak House. On an impulse, while undecided about a career, Richard undertakes to "become an MRCS." He had spent eight years at a public school and "learned to make Latin verses to perfection," but he "never had much chance of finding out for himself what he was fitted for ... and was never guided." However, "the more he thought of it, the more he felt that his destiny was clear; the art of healing was the art of all others for him." He was apprenticed to Mr Bayham Badger, "who had a good practice at Chelsea, and attended a large public Institution besides." $\mathrm{He}$ received Richard into his house and undertook to "superintend his studies."

Later Richard "felt languid about the profession" and confessed that "he had misunderstood his inclinations." He considered changing to the legal profession, but wavered, finally deciding to leave medicine when he was "obliged to spend twelve pounds, at a blow, for some heart-breaking lecture fees." (At this time, parish surgeons earned as little as $£ 20$ a year.)

\section{Postgraduate career choices}

Dickens's doctors had four main avenues of career choice after qualification. Those with financial backing might enter general practice, possibly with the prospect of appointment to an institution. The young doctor without means was forced to consider seeking appointment as a parochial surgeon or to join the army or, worse, the navy as a ship's surgeon. Allan Woodcourt, the young medical hero of Bleak House, initially served as a navy surgeon, then became a parochial surgeon after he had wooed and married 